\title{
DITADURA MILITAR: ECOS EM ENUNCIADOS NO GÊNERO CHARGE
}

\author{
Tiago Souza Monteiro de Andrade
}

FATEC/UNIESP, Presidente Prudente, SP. E-mail: tygerstone@ig.com.br. CNPq - Conselho Nacional de Desenvolvimento Científico e Tecnológico

\section{RESUMO}

Este trabalho, inserido no campo da Linguística Aplicada e dos Estudos da Linguagem, objetiva analisar os elementos constitutivos do gênero charge se articulam para provocar efeitos de sentido e, ainda verificar como um acontecimento histórico passa a ser discursivizado no meio social. O corpus é constituído por três charges, a partir do tema em comum da ditadura militar brasileira. Para as análises propostas, a pesquisa conta com o suporte teórico-metodológico da Análise do Discurso de orientação francesa, utilizando-se das categorias aforização propostas por Maingueneau. A charge corresponde a um gênero que possui relação direta com a memória e com o caráter sócio histórico. Nesse sentido, este trabalho justifica-se por investigar um gênero que nasce do diálogo com outros gêneros veiculados pela mídia, apresentando críticas e subentendidos e exigindo do leitor conhecimentos prévios.

Palavras-chave: Análise do discurso. Produção de sentido. Efeitos de sentido. Gênero charge. Ditadura militar.

\section{MILITARY DICTATORSHIP: ECOS IN STATEMENTS IN THE GENDER CHARGE}

\begin{abstract}
This work, inserted in the field of Applied Linguistics and Language Studies, aims to analyze the constituent elements of the genre charge articulate to induce effects of meaning and also to verify how a historical event becomes discursive in the social environment. The corpus is consisted of three charges, based on the common theme of the Brazilian military dictatorship. For the analysis proposed, the research has the theoretical-methodological support of French Discourse Analysis, using the categories aforizacion and hyperenunciador proposed by Maingueneau. The cartoon corresponds to a genre that has a direct relationship with memory and socio-historical feature. In this sense, this work is justified by investigating a genre that emerges from the dialogue with other genres conveyed by the media, presenting criticisms and sub-understandings and demanding from the reader previous knowledge.
\end{abstract}

Keywords: Discourse analysis. Production of meaning. Effects of meaning. Gender charge. Military dictatorship. 


\section{INTRODUÇÃO}

Seguir pela carreira acadêmica, exige do pesquisador uma série de atribuições: disciplina, comprometimento, perspicácia, paciência e curiosidade. Após a constituição do corpus, ele se depara com a árdua tarefa de verificar a qual teoria deverá utilizar. Para isso, tem que ter a consciência de que é o próprio corpus que anunciará a(s) teoria(s) que melhor nele se aplicará(ão).

Considerando essas ideias, este trabalho é fruto das discussões realizadas no curso Discursos em diferentes dispositivos midiáticos: perspectiva enunciativo-discursiva -, oferecido pelo Programa de Estudos Pós-Graduados em Linguística Aplicada e Estudos da Linguagem - LAEL.

O jornal, enquanto suporte, veicula diariamente textos das mais diferentes naturezas que tratam de assuntos diversos. A charge, por exemplo, é um dos gêneros veiculados nesse suporte, apresentando-se como um texto que expõe de forma crítica e humorística diferentes assuntos no contexto de uma sociedade, por meio uma linguagem que conjuga o verbal e o visual. Ela se utiliza dessa linguagem para construir sua argumentação. Nesse sentido, o projeto discursivo-enunciativo desse gênero é constituído de forma a provocar determinados sentidos, de acordo com momento sócio histórico em que se encontra.

Metodologicamente, o corpus foi constituído por três charges, a partir do tema em comum da ditadura militar brasileira. Para as análises propostas, a pesquisa conta com o suporte teóricometodológico da Análise do Discurso de orientação francesa, utilizando-se das categorias de aforização e de hiperenunciador propostas por Maingueneau (2008).

A charge corresponde a um gênero que possui relação direta com a memória e com o caráter sócio histórico. Nesse sentido, este trabalho justifica-se por investigar um gênero que nasce do diálogo com outros gêneros veiculados pela mídia, apresentando críticas e subentendidos e exigindo do leitor conhecimentos prévios.

Este trabalho objetiva analisar os elementos constitutivos do gênero charge se articulam para provocar efeitos de sentido e, ainda verificar como um acontecimento histórico passa a ser discursivizado no meio social.

$\mathrm{O}$ artigo encontra-se estruturado em quatro sessões. Na primeira, é feita a apresentação das informações basilares do trabalho; a segunda expõe o referencial teórico a respeito da teoria proposta; na terceira, é feita a análise do corpus e, na sequência, as considerações finais.

\section{FUNDAMENTAÇÃO TEÓRICA}

\subsection{Charge: aspectos do gênero}

De acordo com Maingueneau (2006), a formulação da categoria de gênero se dá a partir do conceito de cena de enunciação, havendo a divisão em três níveis interdependentes: a cena englobante, a cena genérica e a cenografia. É necessário considerar que, no interior da Análise do Discurso - $A D$, a questão da subjetividade enunciativa, no que diz respeito às instâncias de enunciação do sujeito, é vista a partir da consideração dos lugares sociais e de suas implicações com a rede de lugares discursivos em que os falantes se colocam para enunciar. $O$ autor aponta os lugares e as práticas histórico-sociais como decisivos para as situações em que o gênero se manifesta, uma vez que se trata de uma atividade social de um tipo particular.

O gênero charge traz na sua constituição a marca da interdiscursividade, já que assume, ao transitar pelos discursos jornalístico e humorístico, características de ambos.

Conforme Romualdo (2000, p. 21), a charge é compreendida "como o texto visual humorístico que critica uma personagem, fato ou acontecimento político específico. Por focalizar uma realidade específica, ela se prende mais ao momento, tendo, portanto, uma limitação temporal". Desse modo, se o leitor não apresentar conhecimentos prévios sobre contexto de produção, a leitura pode ser comprometida. 
Segundo Teixeira (2005), seu tom jocoso a torna transgressora. De acordo com o autor, uma transgressão que é boa para o jornal, o é também para o leitor. Trata-se de uma estratégia que proporciona uma transgressão diária e "uma 'travessura' acima de controles e regras, além do tédio, da mesmice e da chatice do dia-a-dia". (TEIXEIRA, 2005, p. 14).

Possenti (1998) assevera que nem sempre todo humor é progressista e, desse modo, revolucionário. Todavia, conforme o autor, o humor político tende a ser crítico. Este, por sua vez, é retratado nas charges, que, perpassando entre o discurso jornalístico e o discurso humorístico, assume uma postura mais crítica da realidade em relação ao acontecimento que lhe serviu de inspiração.

$O$ intuito do gênero charge é 'atacar' como o seu nome em francês indica. Esse gênero tem a função social de criticar situações do dia-a-dia de contextos políticos e sociais, por meio do humor gerado por vários recursos linguístico-discursivos. Nesse sentido, pelo fato de haver esse teor político, a charge não é tão simples de ser compreendida e o leitor deve ter conhecimentos prévios para ter a possibilidade de construir sentidos. Segundo Espindola (2001, p.110-111), "o leitor deve identificar os personagens e os fatos a que o texto faz referência, o contexto sócio, histórico e político do fato (quando houver), as circunstâncias, os elementos linguísticos (se houver) e as possíveis intenções do chargista".

Desse modo, a constituição do projeto enunciativo-discursivo do gênero charge mostra-se relevante na medida em que, na sua elaboração, tendem a ser entrelaçados aspectos sociais, históricos, culturais e políticos de uma sociedade.

\subsection{Aforização e Hiperenunciação: conceitos fundamentais no percurso teórico}

Maingueneau (2010) defende a importância do texto para as análises linguísticas, apresentando a ideia de aforização para tratar de um dado tipo de enunciado: aqueles que não "decorrem de um regime de enunciação específico" (MAINGUENEAU, 2010, p.12). Corresponde a enunciados sem texto, isto é, de aforizações. Conforme o autor, a aforização tem um funcionamento enunciativo distinto do instituído pela enunciação textualizante. Em outros termos, a lógica de funcionamento de enunciados com provérbios, slogans e máximas difere-se da lógica de funcionamento de um texto.

Para se tratar de uma aforização, o enunciado precisa responder a uma série de critérios, os quais são responsáveis pela alteração no status pragmático do enunciado aforizante, fazendo com que este se diferencie do status de enunciados textualizantes, podendo ser parte integrante de um texto. Na aforização, não ocorre o estabelecimento de papéis e, desse modo, não se pode falar em enunciadores. Segundo Maingueneau (2010, p. 13), "a aforização tem como efeito centrar a enunciação no locutor".

Esse caráter aforizante dos discursos pode, na instância da enunciação, sofrer alterações situacionais, resultando no enfraquecimento ou no aumento ou até mesmo impedir que um dado enunciado adquira estatuto aforizante.

Ao veicular por vários gêneros, a aforização mantém fiel ao seu enunciado de origem. Todavia, há alguns enunciados que resultaram um destaque inicial, porém foram modificados e/ou adaptados com a finalidade de atenderem uma necessidade pragmática do enunciador. Estas são as sobreasseverações, que correspondem a enunciados destacados que representam uma tomada de posição no campo discursivo, implicando uma amplitude na figura do enunciador.

\section{ANÁLISE DO CORPUS: sob as lentes da análise do discurso}

Com base nas discussões feitas na seção teórica, apresentamos o percurso metodológico assumido neste artigo. 
O corpus foi constituído por três charges retiradas de diferentes sites da Internet $^{1}$. O critério de seleção foi a busca de charges que versaram sobre o contexto da ditadura militar brasileira, cujos enunciados fossem asseverados e/ou destacados. Cabe elucidar ainda que foram comtemplados outros textos pesquisados e publicados das quais as charges se originaram.

Quanto aos procedimentos de análise, realizamos a descrição, a análise e a interpretação do enunciado verbo-visual de cada uma das charges, além do conhecimento prévio requerido do leitor, a fim de se compreender os possíveis efeitos de sentido produzidos pelo projeto enunciativo-discursivo do corpus.

Figura 1. Militar no poder: 50 Tons de chibatadas

\section{TONS DE CHIBATADAS}

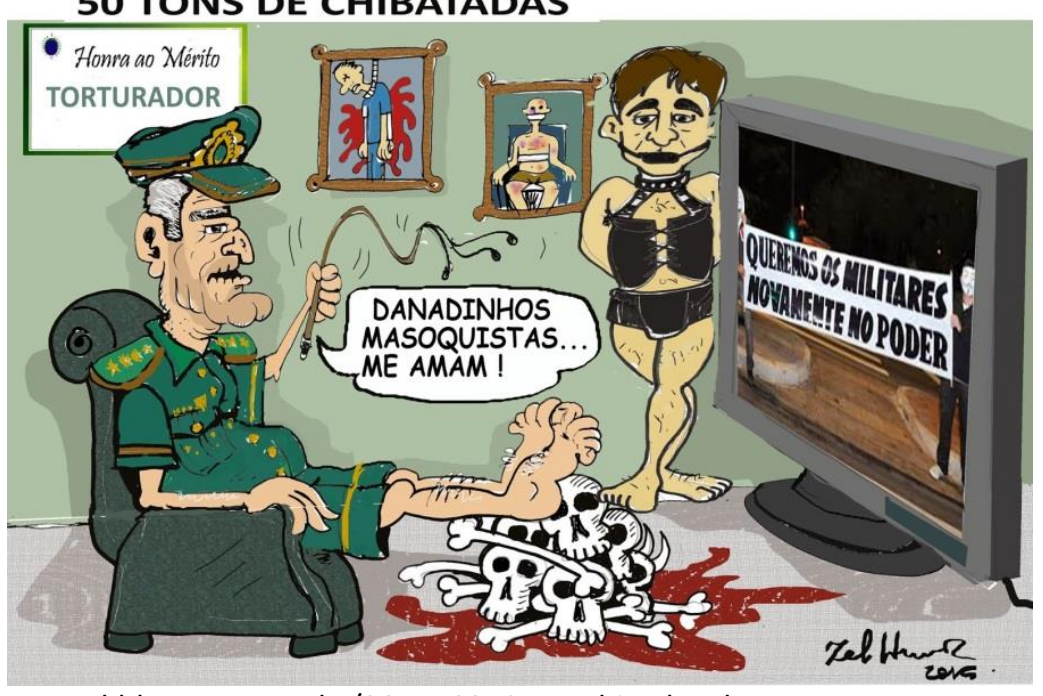

FONTE: <http://zelhumortotal.blogspot.com.br/2015_03_01_archive.html>.

A figura 1 intitulada Militar no poder: 50 tons de chibatadas apresenta dois personagens: sendo um sentado em uma poltrona em frente a uma TV muito grande com uma mensagem que diz "Queremos os militares novamente no poder". Este personagem, vestido de militar, responde a mensagem dizendo "Danadinhos masoquistas ... me amam!". Além disso, encontra-se com os pés sobre uma pilha de ossos e com um chicote em uma das mãos. O outro personagem se encontra em pé ao lado da TV com apetrechos de sex shops, sugerindo apreciar procedimentos masoquistas.

O título da charge remete ao filme 50 Tons de Cinza, longa que tratou da prática de procedimentos masoquistas. Nesse sentido, para o leitor compreender os efeitos de sentido provocados pelo projeto enunciativo-discursivo, ele precisaria ter esse conhecimento prévio.

${ }^{1}$ As informações completas sobre o site encontram-se na seção Referências Bibliográficas deste trabalho. 
Figura 2. Cordão da Mentira

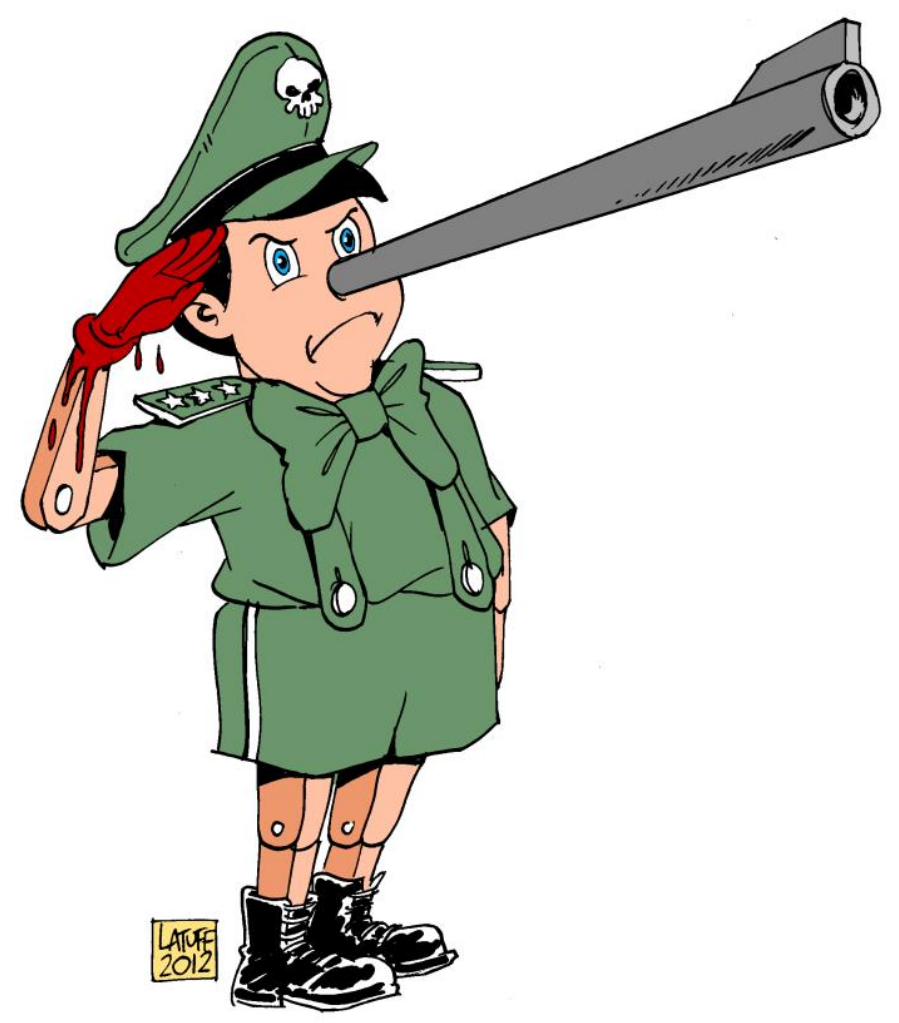

FONTE: <https://latuffcartoons.wordpress.com/tag/ditadura-militar/>.

A figura 2, Cordão da mentira, apresenta uma personagem em pé, vestida com uniforme militar e com o nariz em forma de cano de uma arma. Além disso, apresenta-se em posição de continência, procedimento este que indica obediência. Caber elucidar que o leitor, para identificar os efeitos de sentido produzidos pela charge, deve se remeter ao personagem dos contos de fadas Pinóquio, que, ao mentir, tem o nariz expandido. Essa charge foi criada em 2012, período em que a Comissão da Verdade sobre os crimes da ditadura militar estava bastante discutida.

Figura 3. Arquivos da Ditadura

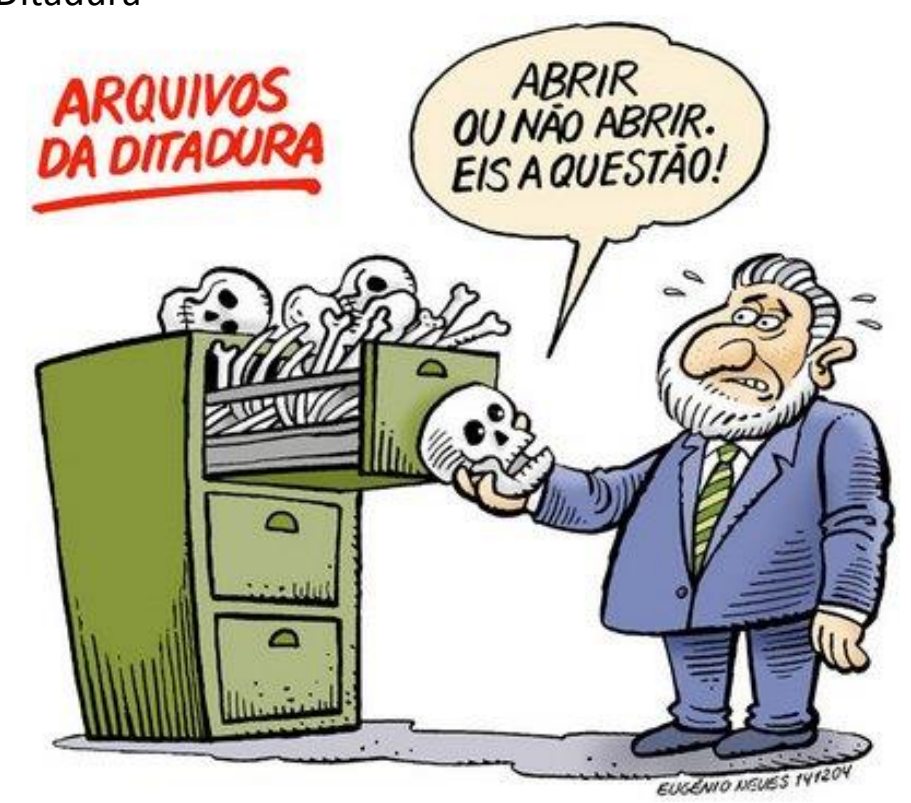

FONTE: $<$ https://andradetalis.wordpress.com/tag/lei-anistia/>. 
Em relação à figura 3, Arquivos da ditadura, é trazida à luz a máxima grega "Ser ou não ser: eis a questão". Essa máxima é recuperada nas palavras de um político que está abrindo um arquivo - Arquivo da Ditadura -. Esse personagem diz "Abrir ou não abrir. Eis a questão."

Como visto, o gênero charge corresponde a uma maneira de propiciar interpretações de elementos linguísticos (textuais) e de elementos extralinguísticos (além-texto) que podem servir para retratar a realidade em determinado momento sócio-histórico-político de uma sociedade de forma crítica e reflexiva.

\section{CONSIDERAÇÕES FINAIS}

A constituição do projeto enunciativo-discursivo da charge mostra-se importante, na proporção em que, em sua constituição, entrelaça aspectos sociais, históricos, culturais e políticos de uma sociedade. Esses discursos, ao dialogarem, situam o leitor no espaço e tempo determinados e o ajudam nessa compreensão.

Após a realização das análises, constatou-se que não seria possível avançar a imanência do texto, se não fossem acionados os conhecimentos prévios ao assunto tratado nas charges. Dentre esses conhecimentos, o de mundo, sendo fundamental para a construção de inferências e, consequentemente, a compreensão dos efeitos de sentido.

O gênero charge, carregado de enunciações, revela o ponto de vista do chargista, desperta o senso crítico-reflexivo no leitor e o mantem atualizado sobre os acontecimentos veiculados pela mídia. Além disso, por meio da constituição da linguagem verbal e não verbal, a produção de sentidos se dá de modo humorístico e irônico, revelando argumentos persuasivos criados a partir de outros discursos em dado momento sócio histórico.

\section{REFERÊNCIAS}

Espindola, Lucienne. A charge no ensino da língua portuguesa. Letr@ Viv@ UFPB. 2001

EUGÊNIO NEVES. Arquivos da ditadura. Disponível em: < https://andradetalis.wordpress.com/tag/lei-anistia/>. Acesso em: 15 mar. de 2017.

LATUFF CARTOONS. Cordão da mentira. Disponível em: < https://latuffcartoons.wordpress.com/tag/ditadura-militar/>. Acesso em: 15 mar. de 2017.

MAINGUENEAU, Dominique. Análise de textos de comunicação. Trad. Maria Cecília Souza-e-Silva e Décio Rocha. 5. ed. São Paulo: Cortez, 2008.

. Cenas da enunciação. Org. Sírio Possenti e Maria Cecília Pérez de Souza-e-Silva. São Paulo: Parábola Editorial, 2010.

. Doze conceitos em Análise do Discurso. Org. Sírio Possenti; Maria Cecília de Souza-e-Silva. Trad. Adail Sobral [et al.]. São Paulo: Parábola Editorial, 2010.

POSSENTI, S. Os humores da língua. Campinas: Mercado de Letras, 1998.

ROMUALDO, Edson Carlos. Charge jornalística: intertextualidade e polifonia: um estudo de charges da Folha de São Paulo. Maringá: Eduem, 2000.

TEIXEIRA, L. G. S. Sentidos do humor, trapaças da razão: a charge. Rio de Janeiro: Edições Casa de Rui Barbosa, 2005. 
ZEL HUMOR. Militar no poder: 50 tons de chibatadas. Disponível em:< http://zelhumortotal.blogspot.com.br/2015_03_01_archive.html>. Acesso em: 15 mar. de 2017. 